\title{
Armët e Greqisë dhe fqinjëve të saj ballkanikë, në periudhën osmane
}

\author{
Robert Elgood \\ (përkth. Elda Dakli)
}

\section{Armëpunuesit e Tetovës, Dibrës dhe Elbasanit}

Shënim: Materiali është marrë nga kap. XV i librit "Armët e Greqisë dhe fqinjëve të saj ballkanikë, në periudhën osmane", me titull në origjinal "THE ARMS OF GRECE AND HER BALKAN NEIGHBORS IN THE OTTOMAN PERIOD”. Ky përkthim vjen në revistën tonë me lejen e autorit Dr. Robert Elgood dhe të fi nancuesve të botimit vëllezërit Yiannis dhe Vassilis Stephanis.

Fotografitëdhefotografëtjanësimëposhtë:

Fotografia 261 marrë nga Pitt Rivers Museum, University of Oxford - fotografi Malcolm Osman.

Fotografitë 262 - 270 nga Stephanidis Foundation, Athens - fotografi - Dr. Klaus - Valtin von Eickstedt. 


\section{Albanon}

\section{Revistë kulturore}

Shqipëria veriore dhe Kosova, gëzonin lidhje të ngushta me Italinë dhe për rrjedhojë ishin teknikisht më të përparuara se pjesa më e madhe e Perandorisë Osmane. Pisqollat mendohet të kenë hyrë në Shqipëri në mënyrë masive në shekullin XVII, pothuaj në një kohë me rrethimin e Kretës (asokohe Candia), kur shumë shqiptarë u rekrutuan nga venecianët. Calina (shum. caline) ishte fjala shqipe e përdorur për një pisqollë, prodhuar në veri të Shqipërisë dhe në Kosovë, midis shekujve XVII-XIX; fjala mendohet të ketë prejardhjen nga italishtja acciarino ose azzalino, që do të thotë një mekanizëm çarku (shih f. 95-96). Edhe ushtria turke rekrutonte shqiptarë dhe pisqollat, ndonëse qenë një risi, filluan të përdoreshin në masë. Vendbanime të ndryshme përdornin fjalë të ndryshme për armët dhe për rrjedhojë e njëjta armë shqiptare mund të ketë disa emërtime të pranueshme.

Në Shqipërinë qendrore, përfshirë qendrën e prodhimit të Elbasanit, pisqollat mbuloheshin me fletë bronzi dhe kishin emrin përshkrues 'verdha. ${ }^{1}$ Fjala do të thotë 'e verdhë' në shqip, dhe emërtimi përdorej për pisqollat e holla, thuajse të drejta, të veshura me bronz, me bishtthin e dorezës me majë, që në anglisht njihen si rat-tail dhe në italisht coda da topo (bisht miu). Vjershëtarët shqiptarë i quanin këto "gjarpnusha Stamolli”, fjalë për fjalë "gjarpër Stambolli”, çka tregon për një lidhje me Stambollin. Në të vërtetë, Stambolli prodhonte dhe eksportonte armë në shekullin XIX, por ka pak të ngjarë që këto pisqolla krahinore të jenë prodhuar atje dhe emri mund të jetë një hiperbolë e fushës letrare ose tregtare.

Fig. 262 Pisqollat e Elbasanit me miquelet lock (çarqe spanjolle, shën. i përkth.). Tyta është e zbukuruar me pika dhe katrorë bronzi, të cilat imitojnë dekorin e atyre europiane, me marka të imituara.

1 Çaushi, 1962, pp. 261-62.. 


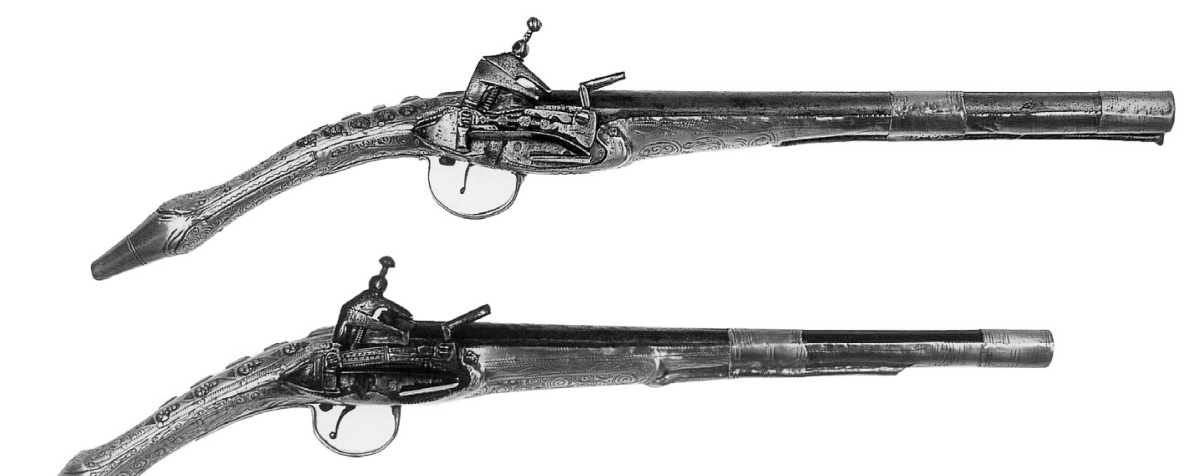

Fig. 263.264 Pisqollat bisht-miu (rat-tail) të Elbasanit, me dorezë të drunjtë, mbuluar plotësisht me fletë bronzi të skalitura. Veshat e rrushit të stilizuara me argjend në dorezë, me gjasë janë kopjuar nga motivi i njohur i Janinës, me argjend.

"Gjarpnusha” me raste përdoret më vete, me kuptimin pisqollë. Emërtimi serbo-kroat për këto pisqolla të Shqipërisë qendrore është silja. ${ }^{2}$

Si mund të përcaktojmë se çfarë periudhe i përkasin këto pisqolla? Ato që janë pothuajse të drejta me një dorezë fare pak të harkuar, i takojnë gjysmës së parë të shekullit XVII dhe ndjekin modelin e pisqollave italiane, ndërsa ato me një dorezë me hark më të theksuar, i përkasin gjysmës së dytë të shek. XVII dhe fillimit të shek. XVIII. Modelet e fillimshekullit të XVIII, kanë një buton në pjesën e pasme, që zgjerohet gradualisht dhe ndërthuret me pjesën e pasme, duke i dhënë asaj formën e një koni të mprehtë me majë. Dekori i dorezave të bronzit bëhet më pak i ngarkuar në modelet e mëvonshme. Tytat e hershme në këto armë janë të zbukuruar me ar ose argjend, me siguri për të pasqyruar ngarkesën e tepruar të pushkëve osmane dhe importeve të Luigjit XIV, me motivin e "rrethimit tëVjenës", duke lënë të kuptohet në këtë mënyrë se kishte edhe një treg eksporti për to; por në gjysmën e dytë të shek. XVIII, doza e dekorimit bie dhe ajo që mbetet është vetëm kompozimi modest $\mathrm{i}$ një shiriti të argjendtë ose një tyte cilindrike të zhveshur nga zbukurimet. Ky ndryshim ndoshta pasqyron rënien e vazhdueshme të rangut shoqëror të blerësve të këtyre pistoletave, teksa blerës të mundshëm me të ardhura më të mira kërkonin diçka më të përparuar dhe në modë.

Karadzic, flet për një pisqollë të shkurtër me dorezë bronzi me majë mjaft të përdorur në Malin e Zi në fillim të shekullit të XIX. ${ }^{3}$ Nuk dihet nga i siguronin malazezët këto armë, por dimë se ato prodhoheshin në Elbasan,

2 Curcic, 1944, p. 201.

3 Karadzic, 1953, p. 142 


\section{Albanon}

\section{Revistë kulturore}

gjatë shekullit XIX. Dibra dhe Prizreni, gjithashtu ishin punishte prodhimi. Pisqollat nga Dibra quhen debarskipistolji (serbo-kroatisht), ose në shqip Albanian debarke celine, latuna ose latuna Dibre, që do të thotë “të Dibrës”. Në Muzeun Ushtarak të Beogradit, gjendet një nga këto pisqollat silja, ${ }^{4} \mathrm{e}$ sjellë në vitet e fundit të shek. XIX, e cila përshkruhet nga kataloguesi i asaj kohe si 'celina debarka'. Ka të ngjarë, që kjo lloj pisqolle të ketë ardhur vërtet nga Dibra, dhe ashtu siç u përhapën fama dhe armëtarët e saj në qendra të tjera, ashtu edhe modeli farkëtohej tjetërkund. Pisqollat e gjata, me tytë të hollë ose bronzi, me pjesën fundore të dorezës në fomë koni me majë, janë karakteristike të Prizrenit dhe Shqipërisë qendrore dhe një pjesë të asaj jugore. Është e vështirë të pikasësh variacionet e imëta ndër modelet e këtyre qendrave të prodhimit. Curcic, tregon një pisqollë që ai e quan një 'calina e Dibrës, e cila ka një fund të dorezës në formë dardhe ${ }^{5}$ dhe është stili i Pec, por duhet të jemi të kujdeshmëm, pasi armëtarët e Dibrës, të cilët kishin reputacion të lartë, po ashtu blinin armë për t’i zbukuruar veçanërisht nga Prizeni $^{6}$, çka mund të jetë një shembull i atij zakoni. Petrovic përpiqet të përcaktojë hapësirën ku prodhohej celina debarka, duke hedhur idenë se në veri ky përfshinte tregjet e Prizrenit dhe Gjakovës, deri në lindje të Shkupit.

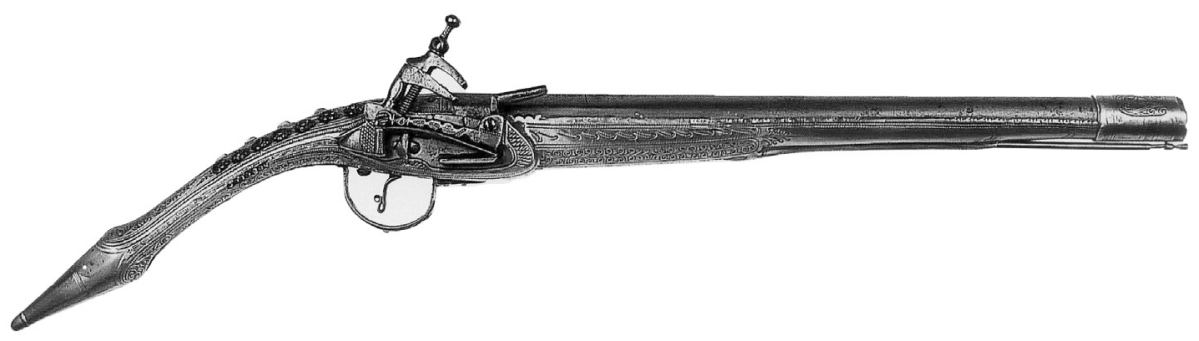

Fig. 265 Pisqollat e Elbasanit, gjysma e parë e shekullit XIX. Punimi i përgjithshëm është më i sofistikuar se ç’ishte zakonisht. Veshja me gurë të çmuar përpara këmbëzës dhe vijëzimet me pika bronzi e rëndojnë motivin standard si vile rrushi.

Meqë nuk e dimë se ç’pamje kishte pisqolla kalkandelen (shih më poshtë), nuk mund të nxjerrim një përfundim në lidhje me Tetovën, ku prodhohej kjo e fundit. Elbasani është prodhuesi jug-perëndimor sipas Petrovic. Megjithatë dimë për qytete të tjerë të vegjël që prodhonin armë, si Berati dhe Tirana, ku armëtarët padyshim do të ndiqnin hapat e qendrave të mëdha armë-prodhuese. Përcaktimi i Petrovic

4 Inv. no. 881.

5 Curcic, 1994, p. 202, top illustration.

6 Lord Byron, Childe Harold's Pilgrimage, 1812, canto 2, v. 58. 
bazohet më tepër në vendbanimet e fundit të armëtarëve të Dibrës që njohim, sesa në modelet që i kanë mbijetuar ditëve të sotme, sidoqoftë duket plotësisht i pranueshëm. Megjithatë, Elbasani dhe Berati ishin të lidhur me Janinën, sidimos nën administratën e Ali Pashës në fundshekullin XVII dhe fillimin e shekullit XVIII dhe do ishte për t'u habitur nëse edhe celina debarka nuk do ish prodhuar atje. Konsulli austriak J. G. Han, mësoi gjatë një vizite të shpejtë në 1865, se prodhimet e Dibrës krahasoheshin me ato të Prizrenit. Ai e përshkruan Dibrën si "një zinxhir i gjatë armëtarësh në një treg të gjatë”?

Shqiptarët kishin qasje në pisqollat e huaja, përfshirë njërën që quhej dunga, me tytë të shkurtër stralli ose pistoletat me perkusion me një kalibër të madh, të dyja të importuara ose kopje e pistoletave europiane. Emri mendohet se rrjedh nga naule, nacke, danacke (diminutive), danaç - burrë i shkurtër, shpatullgjerë, luftarak. Diçka e ngjashme si ide është pisqolla që njihet si cuba; në shumës cubë, emërtimi popullor në shqip për njerëzit e ashpër. Këto zakonisht nuk janë të dekoruara, ndryshe nga pushkët me strall apo pistoletat me perkusion. Cuba, e cila pasqyron preferencën ballkanike për të larë hesapet me goditjen e parë, është zakonisht më e rëndë se pisqolla e xhepit italiane, që njihet me emrin mazzagatto, fjalë për fjalë një "vrasëse macesh". Kjo armë e shekullit XIX përdorej në disa zona të Italisë, por meqë konsiderohej e barasvlefshme me modernen amerikane të njohur si "Saturday night special", ishte e ndaluar. Boccia tregon një mazza-gatto stralli të vogël të viteve $1770 .^{8}$ Pistoletat osmane dhe ballkanike të këtij lloji janë disi të rralla, ndërsa ajo që preferohej ishte një kobure më e madhe me fuqi ndaluese të madhe'. Shqiptarët përdornin edhe fjalën e huaj 'pistoleti', që do të thotë pisqollë.

Tetova ishte një tjetër qytet i rëndësishëm armëprodhues, që renditej ndër më të vjetrit dhe më të njohurit, me një pjesë të madhe të banorëve myslimanë të përfshirë në këtë tregti. ${ }^{10}$ Armëtari i parë në Tetovë quhej Kovacevic: ai u zhvendos nga Dibra në fshatin Lesak, në rrugën kryesore që lidhte Shkupin me Sarajevën, ku punonte tyta pushke. Në Lesak ai tërhoqi vëmendjen e Rexhep Pashait të parë, guvernator i pashallëkut të Kalkandelen (emri turk që kishte marrë Tetova), i cili u impresionua aq shumë saqë e vendosi në një

7 J.G.Han, 1876, p. 152

8 Boccia, 1996. The Katzbalger, literally cat skinner', a Landsknecht sword, shares the same humour.

9 For an 18th-century Balkan mazza gatto see Alexander, 1992, no. 68, p. 124.

10 Much of the information on Tetovo is derived from Petrovic, 1964, Tetovskipuskari. 


\section{Albanon}

\section{Revistë kulturore}

mulli uji që të shponte tyta armësh. Emri i pashait na ndihmon të datojmë këtë ngjarje rreth fillimit të shekullit XVIII. ${ }^{11}$ Të krishterët e Bullgarisë veriore në 1727 ishin të armatosur me pisqollat që njiheshin me emrin kalkandelen. ${ }^{12}$ Duke u nisur nga ky fakt, Petrovic arrin në përfundimin se Bullgaria veriore furnizohej me armë nga Tetova, ${ }^{13}$ çka mund të jetë e vërtetë, pasi qyteti në atë kohë kishte një popullsi të konsiderueshme sllavo-ortodokse, ndonëse Bullgaria kishte qendrat e saj të rëndësishme të prodhimit të armëve, Nikopol, Sliven dhe Gabrovo, të cilat ishin mjaft të njohura. Evliya Çelebi admironte dekorimin e shishanas (pushkë turke, shën. i përkth.) që prodhoheshin në Nikopol. Në fillimet e shekullit XIX, Sliveni e furnizonte Stambollin me 6,000-7,000 tyta në vit. Fjala vendore "Islivné" (nga Sliven) ishte një sinonim për një armë fine dhe asokohe qarkullonte një pisqollë bronzi që prodhohej në Sliven - slivanka. Këto pisqolla me strall kanë një mbështjellëse të gjerë argjendi, me një sipërfaqe të vijëzuar sipas modelit të dorezave të Italisë së veriut. Armët e Slivenit eksportoheshin në sasi të mëdha edhe në Persi, Kurdistan, Kaukaz dhe Azinë e Vogël. ${ }^{14}$ Gjenerali Dibich-Zabalkansky, në vitin 1828, e informonte perandorin rus se do të përpiqej të bindte disa nga armëtarët e Slivenit të emigronin në Rusi. ${ }^{15}$ Armët prodhoheshin edhe në Sofie, Shumen, Silistra, Kazanluk, Samokov, Plovdiv, Panagyurishtë, Vidin dhe Vratsa. ${ }^{16}$ Hekuri i Samokovit ishte materiali i preferuar për tyta pushke. Mendohet se armët që vinin nga këto qendra të prodhimit, e gjenin rrugën deri në Greqinë lindore.

Aty nga viti 1786, Tetova kishte 450 punishte që prodhonin armë zjarri, por nuk gjendet asnjë e dhënë karakteristike që të identitifikojë produktin e këtij qyteti. Vetë qyteti ishte i vogël dhe i lidhur mjaft mirë me rrugë deri në Shkup, Nish dhe Shkodër. Nga tregjet e Gornja carsija-s, tregu i sipërm i myslimanëve, armët e klasit të parë dhe koburet tregtoheshin anekënd nëpër Perandorinë Osmane.

Qyteti kishte reputacion ndërkombëtar, dhe armët e Tetovës veçanërisht kur farkëtoheshin nga usta Hasani, transportoheshin me karvan deri në Irak, Persi dhe Indi. Në Donja carsija ose tregun e poshtëm, kishte disa punishte dhe në zonën që njihet me emrin Cargoj, tytat shpoheshin me dorë, në

11 Petrovic, 1975-76.

12 Po aty, p. 42.

13 Petrovic, 1989, Dibra, p. 2.

14 Daskalov and Kovacheva, 1989, p. 18

15 Po aty, p. 18

16 Kozlovski, 1981 


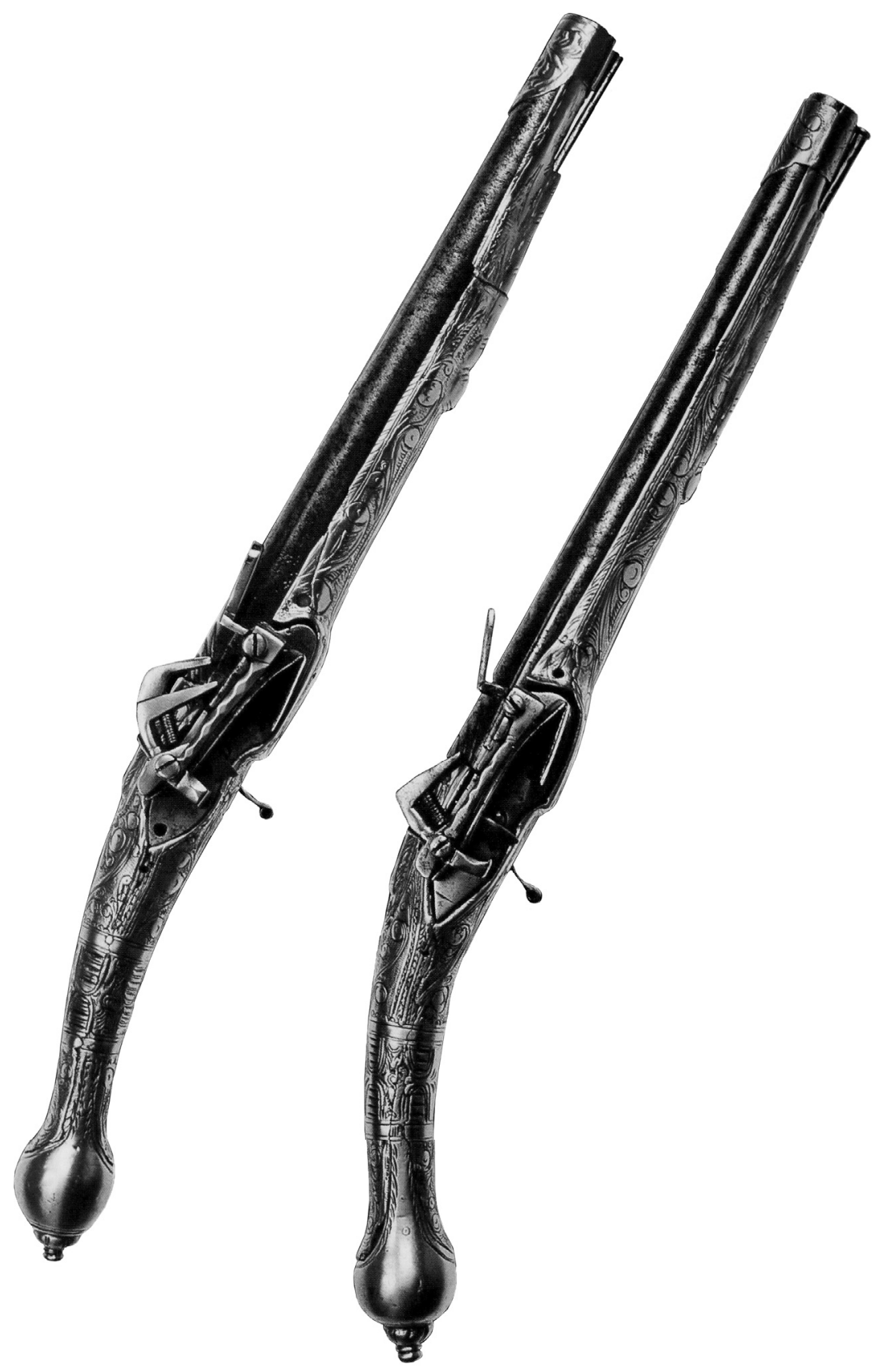

Fig. 266, 267 Dy pisqolla të Shqipërisë qendrore, dhe dorezë me fund vezak. Petrovic sugjeron se janë të Dibrës, dhe i përkasin gjysmës së dytë të shekullit XVIII. Një mundësi tjetër është që këto të jenë kopje elbasanase të pisqollave epirote roka. 


\section{Albanon}

\section{Revistë kulturore}

kabinat përbri kishës duke përdorur fuqinë e ujit nga lumi Pena. Këto punishte ishin pronë e armëpunesve të pasur nga Gornja carsija. Të gjithë armëpunuesit ishin anëtarë të shoqërisë së armëpunuesve të vendit, esnafi Tufekdzijski. Në një zonë të njohur për mungesën e rendit, kërkesa për armë ishte një nga faktet më të sigurta të jetës së përditshme. Gjendja anarkike nxiti zhvillimin e industrisë së armëve, ndërsa ritmi i ngadaltë i rritjes së ekonomisë nën pushtimin osman dhe fuqia e ulët blerëse e tregjeve lokale, mbronte këtë industri familjare nga trysnia e konkurrencës që vinte prej Europës industriale.

Nga fillimi i shek. XVIII, u shfaqën në skenë dy familje armëpunuesish shqiptare, Karo dhe Kajkus, të cilët ishin renegatë të ushtrisë osmane. Një jatagan me nënshkrimin "punë e Karo’s, i zoti Ahmedi" gjendet në koleksionin mbretëror të Malit të Zi. ${ }^{17}$ Islam Karo (1781- 1878), një armëtar dhe tregtar, çonte armët e tij dhe të armëtarëve të tjerë në Aleppo një herë në vit dhe nëse nuk ia dilte t'i shiste aty, mandej i çonte tutje deri në Egjipt. ${ }^{18}$

Nga mesi i shekullit XIX, armëtarët bullgarë u nxorrën jashtë loje nga armët me perkusion belge dhe ky zej u shkri kur pushkët Uinchester dhe Peabody-Martini të porositura nga ushtria osmane nëpër fabrikat e Europës perëndimore, përmes Tetovës dhe Nevrokop-it filluan të prodhoheshin në një version të Martini rifle. Rebelët që luftuan kundër turqve në 1876, mbështetëshin kryesisht tek "bear killers" apo shishanas e tyre të vjetra. Georgi Makazchiev i Slivenit prodhoi një armë gjahu me perkusion, me një tytë, për një zonjë; ajo peshonte $2 \mathrm{~kg}(4.14 \mathrm{lb})$ dhe fitoi një medalje të artë në ekspozitën kombëtare të Plovdivës, më 1892, por nuk dimë për armë të tjera që të jenë prodhuar prej tij dhe ai nuk njihej si armëtar profesional. ${ }^{19}$

Më tutje në jug, Elbasani, ishte një nga prodhuesit e mëdhenj të armëve dhe pajisjeve. Në 1466, gjatë një fushimi kundër Skënderbeut, sulltan Mehmeti II ndërtoi një kala mbi rrënojat e qytetit antik të Skampës, të cilin e quajti Ilbasan, që ka kuptimin "vend sundues”. Nga shekulli XVII, Elbasani ishte kthyer në një nga qytetet kryesore të rajonit, me rreth 2,000 banesa: qyteti pozicionohej mirë mbi rrugën kryesore tregtare që lidhte Adriatikun dhe gjirin e Selanikut me qytetet fqinje të Beratit, Krujës, Ohrit dhe Durrësit. Ai mbahej për epërsinë e argjendarëve të tij, të cilët dekoronin armë dhe prodhonin artikuj argjendarie. Evliya Çelebi e vizitoi qytetin në 1662 dhe do

17 Vukmanovic, 1961, p. 12

18 Petrovic, 1988-89, citing oral tradition collected in Tetovo in 1955

19 Daskalov and Kovacheva, 1989, p. 20 
të shkruante: "ka shumë shqiptarë që prodhojnë mburoja, shigjeta, dhe harqe. Vendi është i famshëm për prodhimin e armëve cilësore."

Më tej vazhdonte: "Një treg i madh popullor mbahet në Elbasan çdo të diel. Me këtë rast, mijëra njerëz, të mëdhenj e të vegjël, burra e gra, viijnë nga fshatrat e zonat, qytetet e kalatë përreth. Me zor arrin të çash rrugët ... Çdo të diel, me pak fjalë, Elbasani dyndet me njerëz dhe stoliset me mallra, çka e bën këtë qytet tregtie nusen e Shqipërisë dhe Rumelisë... Veçanërisht rrugët në tregun e cohërave dhe në tregjet e shigjetapunuesve, harkëtarëve, thikapunuesve dhe shpatapunuesve, janë rrethuar me mana, pemë të larta çinari dhe shelgje lotues e mijëra trina hardhish, në mënyrë që të gjithë tregtarët të kenë mundësinë të shesin artikujt e tyre të ulur nën hije". ${ }^{20}$

Pasojat e rënies së autoritetit qendror të Perandorisë Osmane ishin të dukshme për Pouqueville në fillim të shekullit XIX:

"Pamja e jashtme e luginës do ta çojë këtë kalimtar të huaj në përfundimin e natyrshëm se banorët e Elbasanit janë të dhënë pas asaj industrie dhe të mirave të saj: por me të ngritur sytë drejt vargjeve të kodrave qü rrethonin qytetin, një zinxhir $i$ gjatë kullash dhe fortesash, të ngritura mbi majëmalet më të paarritshme, do ti zbulojë atij gjendjen e mjeruar të armiqësisë dhe alarmit në të cilën elbasanasit e ngratë kalojnë ditët e tyre. Roje, grupe të vegjël dhe brigada luftëtarësh, të instaluar në këto kulla, ruajnë fushat dhe trojet përreth, për të lajmëruar në rast se shfaqen dhe afrohen fiset fqinje, me të cilët ata janë në luftë të përjetshme. Në sinjalin e parë të rrezikut çdo burrë është gati për betejë: dhe kjo gjendje frike dhe shqetësimi, më shkatërrimtare sesa konfliktet aktuale, por jo të përhershme, në kombet europiane të asokohe, pati një ndikim tepër të lig mbi popullatën. Kështu, në vend të 8,000 familjeve ose 40,000 banorëve, shifër me të cilën ishte regjistruar popullsia e Elbasanit, popullsia e atij vendi në fakt nuk $i$ kalonte 4,000, dhe dallohej për egërsinë ashpërsinë dhe varfërinë. Kjo gjendje e mjeruar, pasojë e padiskutueshme e keqqeverisjes, në vend që të zbusë administrimin e sunduesve turq të luginës, vetëm sa bën me të idhtë brutalitetin e tyre të natyrshëm dhe $i$ bën ata të padrejtë dhe të pamëshirshëm karshi të krishterëve ortodoksë, të cilët $i$ ishin nënshtruar zgjedhës tiranike. "21

Pouqueville e përshkruante popullsinë jashtë Elbasanit si "Gegë trima, krenaria e luftëtarëve shqiptarë. Në atë zonë të gjithë kanë një sjellje të egër; të gjithë janë të armatosur: as vetë gratë, të cilat përçmojnë vellon ose boshtin, nuk $i$ sheh kurrë pa një palë pistoleta apo armë të tjera të fshehura nën rrobë." Ka edhe

20 Dankoff and Elsie, 2000, p. 175

21 Pouqueville, 1820, p. 23 


\section{Albanon}

\section{Revistë kulturore}

burime të tjera që flasin për gratë që luftojnë përkrah burrave në mbrojtje të fshatrave të vet. Grave suliote iu mësohej të përdornin mushqetat, por roli i tyre i përditshëm ishte t'u shpinin burrave ujë dhe municione. "Shpatet veri-perëndimore të maleve të Zagorisë, qü zgjaten drejt luginës së Tepelenës, popullohen nga shqiptarë me një temperament të ashpër, gratë e të cilëve janë luftëtare."22

Për shekuj me radhë, Elbasani ka qenë i lidhur ngushtë ekonomikisht dhe politikisht me Janinën dhe në fillimet e shekullit XIX, Ali Pasha mori kontrollin e zonës, dhe e zhvilloi tregëtinë dhe fortesat e saj. Leake përshkruan Abdulla Pashën e Elbasanit tek mbërrin në Tepelenë për t’i bërë nderime Ali Pashës në Janar 1805..$^{23}$ Armëpunuesit e qytetit gjendeshin në dy zonat tregtare, në atë të Uruneve dhe në zonën e hapur ose në shehin e Leshnave siç quhej në atë kohë. Çaushi shkruan se në çdo zonë kishte nëntë a dhjetë punishte. Ky zej mbikqyrej nga një këshill i përzgjedhur që përfshinte një kryetar dhe dy antarë të esnafeve, të cilët shërbenin për një afat katër-vjeçar. Zeji i armëpunuesve në Elbasan ishte shumë më i madh sesa ai i Janinës. Një listë e armëpunuesve të esnafëve të Elbasanit ka mbijetuar deri në këto ditë dhe përmban 253 emra, ${ }^{24}$ me shumicë muslimane dhe çdo vit kreu kishte detyrën të organizonte ceremoninë e Mevludit për të kremtuar datëlindjen e Profetit. Mevludi lexohej në xhami një ose dy orë para perëndimit. Atyre që ishin të pranishëm në atë çast, u shërbehej sherbet dhe llokum. Me raste, në shtëpinë e njërit prej anëtarëve, organizohej një festë e madhe.

Në mënyrë të pashmangshme shumë nga zejtarët e Elbasanit kishin lidhje farefisnore. Për shembull, djali i Hajrullah Zabzunit, Tahiri, ishte martuar me vajzën e një tjetër armëtari, Abdulla Shingjinit dhe punonte në punishten e vjehrrit. Abdullai i mësoi zanatin dy djemve të tij, Osmanit dhe Salës dhe Ymer Shingjinit, më të cilin mendohen të kenë patur lidhje farefisnore. Edhe djali i Hajrullahut, Ademi, kishte kryer haxh, që të merrte tagrin Haxhi Adem Zabzuni. Ai i mësoi mjeshtëritë e tij vëllezërve të vegjël, Muçit, Ibrahimit dhe Sulës. Armëpunuesit më me emër të shekullit XIX, ishin Osman Dyni, Bim Baxhaku, Lam Zabzuni, Kalem Duka, Muçi Seman Qerosit, Mal Skera dhe Muç Guranjaku. Disa prej armëpunuesve vinin nga fshatrat dhe mbanin emrat e fshatrave si patronim, një praktikë e përhapur në Lindjen e Mesme. Për shembull, armëpunuesi elbasanas Abdulla Shingjini vinte nga

22 Hobhouse, 1813, p. 142

23 Leake, 1835, vol. 1, p. 53

24 The author visited the town several times and was promised a copy; it never came, though he saw a photograph of part of it. 
fshati i Shingjinit, që në ditët e sotme është një rrethinë e Tiranës. Tahir Zabzuni, një tjetër anëtar i esnafëve të Elbasanit, vinte nga fshati Zabzun në zonën e Çermenikës. Artizanët lokalë bënë kalimin nga shkrepja me strall në shkrepjen me perkusion dhe te revolverët dhe pushkët me mbushje me fishekë në fole si Martini, duke i prodhuar këto në mënyrë artizanale në një kohë të admirueshme. Martina ishte veçanërisht e përhapur në Shqipëri dhe mësojmë se Haxhi Adem Zabzuni, i cili kishte trashëguar vetëm zejin e armëve që mbushen nga gryka, ishte i detyruar të shkonte çirak te Salihu-iXhem Katundjes, një tjetër armëtar në Elbasan, për të plotësuar mjeshtërinë e zejit të farkëtimit të foleve të fishekëve. Prodhimi i armëve vazhdoi edhe në shekullin XX, sipas kronikave të esnafëve.

Armëtarët e Elbasanit prodhonin çarqe dhe armë të tjera me pjesë këmbimi / montim. Çarqet priteshin dhe grumbulloheshin mënjanë dhe preferoheshin më tepër sesa çarqet e importuara, të cilat quheshin çerqe deti; çark (shum. çerqe) është emërtimi shqip për një grackë ose çark miu. Armëtarët punonin me argjendarët, të cilët dekoronin armët me bronz, si dhe me punuesit e lëkurës të cilët punonin rripa (fjala e asokohe rryp). Në Berat dhe Elbasan prodhohej një pisqollë që e hasim me emërtime të ndryshëm si "Karberesha", "Karbereshe" ose "Karabereshe". Çaushi i përshkruan këto si pisqolla të llojit të drejtë dhe thotë se dekorimi i bronztë i tyre bëhej në Berat dhe Elbasan. Këto janë pisqollat standarde që preferoheshin në Shqipërinë e jugut dhe morën emër nga suliotët, të cilët i has të ilustruar në shumë portrete dhe piktura bashkëkohore. Emri i këtij lloji pisqolle tregon për mënyrën se si erdhën këto armë në zonë nëpërmjet Karberesheve, një fis i krishterë, burrat e të cilit shërbenin si mercenarë tek venecianët dhe furnizoheshin nga Kotorri. Një tjetër emër më i përdorur për këto pisqolla me tytë e qytë që formojnë një vijë pothuaj të drejtë - si për shembull brass Dibar ose pisqolla e Elbasanit ose Karberesha - është roka, që vjen nga shqipja 'gjuaj, godas ose rrok'. Këto pisqolla janë me origjinë shqiptare ose nga Epiri i veriut, një fakt që konfirmohet nga përdorimi i kësaj fjale prej grekëve. Në të folurën e përditshme serbe të këtyre kohëve roknuti do të thotë të godasësh dikë. Ideja për këtë emër mund të ketë ardhur nga tabanca ose tabanja, në arabisht dhe turqisht për një pistoletë ose revolver, e cila rrjedh nga një fjalë tanimë arkaike, që do të thotë "a shpullë se grusht". Në serbishten e ditëve të sotme, taban është mekanizmi i kyçjes së pisqollës; siguresa është tabanska dascica dhe pllakëza tabanska plocica.

Një tjetër lloj pistolete që prodhohej në Elbasan ishte një version tunxhi i 


\section{Albanon}

\section{Revistë kulturore}

celina debarka ${ }^{25}$. Në 1904 Edith Durham udhëtoi në këto anë dhe bleu nga njëri prej armëpunuesve një pistoletë bronzi "rat-tail" me ndezës stralli, e cila tani gjendet në Muzeun Pitt Rivers në Oxford. Ajo komentonte se ky lloj ishte ende në përdorim nga barinjtë përreth Elbasanit: "Mendoj se këto ishin ndoshta pisqollat e fundit me ndezës stralli që u prodhuan për përdorim në Europë.” Një emër i përhapur për një pisqollë me tunxh shumë të thjeshtë që përdorej në Ballkanin qendror ishte silja. Bjelokosic i përshkruan këto si “armë që bliheshin nga fshatarët për barinjtë e tyre". ${ }^{26}$ Në gjysmën e dytë të shekullit XIX, ekzalia u bë shumë e përhapur në Elbasan.

Esnafët lidhën një marrëveshje me armëpunuesit hungarezë që vinin në Elbasan dhe blenë kariophilis që prodhohej në Hungari (Maxharia). Këto kishin dy forma: kariofilipraxhar ose maxhar, ose hungarian kariophili, dhe kariofiliprift. Kjo e fundit thuhet se mban emblemën e stampuar të një "peshkopi”'. Se çfarë simboli përdorte një peshkop hungarez për dekorim apo vulë prodhuesi nuk dihet më dhe kërkimet e autorit në Budapest nuk nxorrën ndonjë rezultat. Një mundësi tjetër është që emri të ketë rrjedhur nga escopeta, fjala spanjolle për një mushqetë të lehtë ose që kjo armë të ketë patur ndonjë lidhje me fshatin fqinj Episcopi. ${ }^{27}$ Sidoqoftë, fjala shqipe që përdoret rëndom për peshkopin është "prift", kështu që kjo nuk duket shumë e pranueshme. Po të kemi parasysh faktin se emrat e armëve të tjerë osmane janë përshkrues, këto emra ka të ngjarë t'i referohen formës ose dekorit të tyre.

Nuk dihet se kur filluan lidhjet tregtare të Hungarisë me Elbasanin, por historiani modern Temesvary shkruante se, "Në Hungari, veç eksportit të armëve, mund të vërejmë fluksin dhe praninë e vazhdueshme të produkteve perëndimore, ballkanase dhe turke, madje edhe perse $e^{28}$ - pavarësisht nga një rritje e shpejtë e prodhimit të armëve në Hungari si rrjedhojë e luftës për çlirim në shekullin XIX. Deri në Arabi, beduinët i konsideronin armët hungareze që njihen me emrin 'el Majar', të krahasueshme vetëm me 'el Lazzary, ${ }^{29}$ çka flet për një prodhim masiv të tyre."

Luftëtarët shqiptarë ishin përfshirë masivisht në luftën me Pasvantoglu në Vidin, dhe në luftërat e shekullit XIX që përfshinë serbët dhe hungarezët,

25 Çaushi, 1962, p. 262

26 Bjelokosic, 1898, 3/3, p. 38. See also Petrovic, 1974

27 William Turner, 1820, vol. 1, p. 125, mentions two new watermills, two Greek churches and the stupendous view from the village, but there is no evidence of gun making

28 Temesvary, 1983, p. 12 


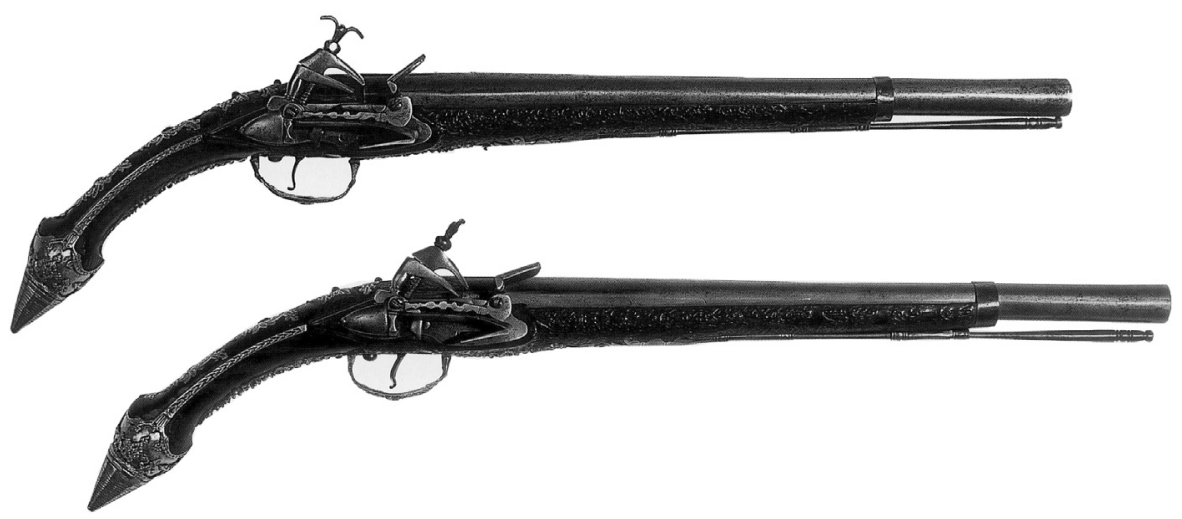

Fig. 268. 269 Dy pisqolla celina shqiptare, me ndikim të dukshëm të modelit italian, shekulli XVIII. Fundet me majë të dorezave janë një tipar dallues që flasin për një qytet të caktuar, me gjasë, Tetova ose Dibra.

midis Turqisë, Russisë dhe Austrisë, dhe ky mund të jetë një shpjegim për praninë hungareze. Ka edhe gjasa që hungarezët të kenë prodhuar armë të llojit shqiptar, sidomos për arsyen se këto do të ishin armë të njohura edhe për serbët e shumtë që ishin arratisur në Hungari për të kërkuar mbrojtjten e Habsburgve, ndonëse serbët përdornin pushkën austriake me aq dekor tunxhi ne qytë sa mund të përballonin financiarisht.

Në çdo rast esnafët e Elbasanit i lejonin hungarezëve qarkullimin në tregun vendor dhe këta të fundit kishin zënë një pjesë të pazarit në Elbasan që quhej Bezistani. Rruga ekziston ende dhe deri vonë njihej si rruga hungareze. Eduard Lear e vizitoi Elbasanin në 1848 dhe në ditarin e tij të udhëtimit përshkruante se si "çdo rrugë është e caktuar për një lloj të vecantë tregtie". ${ }^{30}$ Një tjetër tregues i udhëtimeve të tregtarëve hungarezë në Shqipëri është ura e Maxharit në Shkodër. Esnafët nuk e nxisnin konkurencën midis armëtarëve, prandaj marrëveshja duhet të ketë qenë me përfitime reciproke për të dy palët, çka sugjeron se ose hungarezët kishin mjeshtëri teknike të përparuara ose tregu vendor kishte mungesa armëtarësh. Dimë se çarqet dhe armët prodhoheshin nga armëtarët elbasanas, dhe nëse hungarezët thjesht furnizonin pjesë të armëve, atyre nuk do t’ju ish dashur të banonin në Elbasan. Një tregtar serb i mirëinformuar i tregoi autorit të këtij shkrimi një palaska të shekullit XIX, të një lloji të njohur në Ballkanin jugor, e cila kishte vula që mezi dalloheshin, në buzën e kutisë, dhe mbuloheshin nga kapaku, kur kutia ishte e mbyllur, që sipas tij ishin karakteristike të pisqollave hungareze, por ky është një rast i veçatë.

30 Lear, 1851, p. 94 


\section{Albanon}

\section{Revistë kulturore}

Ka një fshat të quajtur Shpati në Shqipërinë qendrore, në juglindje të Elbasanit, shpatat e të cilit përmenden, me emrin “shpatë", nga Evliya Çelebi në 1670, gjatë vizitës së tij në Berat, pesë orë larg në jug të Elbasanit. Ai përshkruante se si të gjithë burrat betoheshin për shpatën, ${ }^{31}$ Dankoff dhe Elsie sugjerojnë 'içbata, içmata" (për shqipen 'shpatë të asokohe)' dhe citojnë "beli Arnavud ifbata qiliçh”. Një tjetër derivation është spado ose spathe, nga italishtja dhe greqishtja. Nuk kishte qendra të mëdha të prodhimit të shpatave në Shqipërinë jugore, dhe dihet se tehet e shpatave importoheshin nga Venecia. Në 1814 një tregtar anglez me një sasi me tehe shpatash për të shitur, vendosi, se Shqipëria si vend plot ushtarë, ishte treg i mirë, dhe kështu vajti në Prevezë, ku filloi t'i shiste ato.

"Lajmi i shkoi Ali Pashës, i cili bëri be "për gjarprin e zi", betimi i tij i zakonshëm, se asnjë teh nuk do të shitej pa dorëzuar zotëria anglez tek ai një kompliment prej dy dollarësh për secilin: shuma që përbënte saktësisht vlerën e një shpate, ia bëri të pamundur tregtarit që të zbatonte kërkesën e Ali Pashës; kështu ky i fundit çoi lajm te tregtari se kjo punë nuk bëhej. "Nuk bëhet" thirri Aliu. "Do e shoh vetë këtë punë.” U dha urdhëri, që një togë shqiptarësh të vizitonte çdo fshat dhe të shtrëngonte banorët që t’i blinin shpatat me katër dollarë secilën. Këta nuk mund të kundërshtonin komandat e pashait dhe tregtari shpejt pa mallin e tij të shitej. Ali Pasha i dha atij dy dollarë për çdo teh, dhe mbajti kusurin prej dy dollarësh, duke gllabëruar, nëpërmjet këtij akti shtypës, katër mijë dollarë."’2

Në 1848 Eduard Lear bëri një gravurë të dy të fortëve "Gegë Muhamedanë të Elbasanit”. Kur goma indiane prej llastiku i ra atij në dysheme dhe bëri dy kërcime drejt tyre, këta luftëtarë u trembën aq shumë, sa britën 'shaitan! shaitan!', dhe nuk u qetësuan as kur Lear e futi atë në xhep. Nervozizmi i bëri ata të dridhen, çka e acaroi aq shumë Lear sa në fund e humbi toruan, duke përplasur gomën e llastikut në dysheme dhe të dy ia mbathën me të sokëllitur nga ky djall që kërcente. ${ }^{33}$

Elbasani ishte një nga qytetet që kontribuan në prezantimin e armëve turke në Ekspozitën e Parisit të vitit 1867. Gazeta "Turku” që ishte ngarkuar me organizimin e kontributit të Perandorisë Osmane, shkruante: "Okri, Debrei-Bala, Iblissan, në krahinën e Rumelisë; ekspozuesit Usta-Islam, ArslanAbdullah dhe Ibrahim kanë dërguar rripa pushkësh (silahlik), gjerdanë, pistoleta me zbukurimet e tyre dhe çarqe pushkësh dhe pistoletash." Aty nga viti 1890,

31 Dankoff and Elsie, 2000, p. 125

32 Kendrick, 1822, p. 53

33 Lear, 1851, p. 216 
intelektuali shqiptar Sami Frashëri shkruante në Enciklopedinë turke, se shqiptarët ishin të famshëm për farkëtimin e armëve cilësore, dhe Elbasani gjithashtu kishte emër në këtë drejtim. ${ }^{34}$

Peabody-Martini fillimisht u shfaq në Angli më 1871 dhe që në mesin e 1870ës kopja e parë shqiptare e Martinit, në tregun vendës e njohur si Martina ose Huta, u prodhua në Tetovë, në punishten e Bajram Gorgovicës. ${ }^{35}$ Tetova në këtë drejtim ishte përpara Prizrenit, ku më 1882-83 u prodhua Martina e parë (shih f. 193). Nuk dimë nëse Martina e parë që mbërriti në Tetovë ra në duar të ushtrisë turke apo u soll nga Austria a Serbia, por shpejt qyteti fitoi një reputation kaq të madh për Peabody-Martinis të tij sa nëpër Ballkan ato quheshin quheshin thjesht tetovke ose me raste tetovske Martinke. Tetova prodhoi disa lloje të ndryshme Martina. Njëra nga këto kombinonte trupin e një Martine me një tytë Mauseri që ishte sjellë kontrabandë nga Austria dhe Serbia dhe i ishte zgjeruar diametri në Tetovë. Prodhuar në Tetovë po ashtu ishte edhe një karabinë Martini, shumë e përhapur, me kopje të stampës, numrit serial dhe nënshkrimin Peabody-Martini të shtetit turk. Procesi i prodhimit ishte mjaft i specializuar dhe i ndarë në prodhues tytash, prodhues pjesësh pisqolle dhe prodhues qytash. Plumbat prodhoheshin duke përdorur gëzhoja nga Austria dhe Italia ose të mbledhura nga lufta greko-turke e vitit 1884 që rimbusheshin. Baruti sillej nga Metja, në afërsi të Dibrës, ose vinte kontrabandë nga Bujanovaci. Një Martina nga Tetova, e prodhuar nga mjeshtri i njohur usta Islami, fitoi një çmim në ekspozitën ndërkombëtare të Çikagos në 1894, duke vënë në dukje edhe një herë mjeshtërinë e armëtarit tetovar për të punuar me mjete të thjeshta. Armët tetovare tregtoheshin përmes tregjeve të Prizrenit dhe Shkodrës, por përfundimi i hekurudhës që lidhte Selanikun me Shkupin dhe Mitrovicën, në 1873 i çoi armët tetovare në Selanik, ku çmimi i lirë rriti shitjet e tyre. Hekuri për prodhimin e armëve vinte në Tetovë nëpërmjet hekurudhës, por ishte hekur i butë dhe cilësia e tytave shpejt pësoi rënie. Por meqenësë çdo burrë shqiptar donte ta kishte një Martina tetovare sapo e shihte atë, suksesi tregtar i kësaj sipërmarrjeje qe i sigurtë, edhe pse tregu jashtë qytetit po rrudhej dhe Martina e tij shitej kryesisht në Maqedoninë perëndimore dhe në Shqipëri. Tetovke-t shiteshin në Shkup, Dibër dhe Elbasan, dhe tradita na çon të mendojmë se një tregtar me emrin Shaqir i transportonte ato në Gjakovë dhe Pec. Martina-t gjithashtu prodhoheshin në sasi të mëdha në Gjakovë, e cila si Tetova, ishte ende një vend ku mungonte rendi deri në fund të shekullit XIX.

34 S. Frashëri, 1890 


\section{Albanon}

\section{Revistë kulturore}

Në Ballkanin perëndimor, organizatat revolucionare kryengritëse hartuan dhe komplotuan një kryengritje kundër turqve në 1887 . Këto u armatosën me tetovke, ${ }^{36}$ veçanërisht në Maqedoninë qendrore dhe veriore, përreth Porec, Krusevo, Demir-Hisar, ${ }^{37}$ Ohrit, ${ }^{38}$ Kicevës, Prilepit dhe Bitolës, ${ }^{39}$ zona ku nuk gjindeshin pushkët Gras, që përdornin grekët. ${ }^{40}$ Shitjet ishin në dorë të shqiptarëve..$^{41}$ Dy emra njihen si furnizuesit e komitetit revolucionar të Krusevos: Meto Maale dhe Jumer Ismael. ${ }^{42}$ Nëpër Tetovë flitej për një farë "Jusuf-aga xhambas", një term me dy kuptimet: tregtar kuajsh dhe batakçi, mashtrues, që furnizonte rebelët. Edhe kryengritësit e Bitolës furnizoheshin nga Dibra. Turqit zbuluan se armëtari tetovar Ljudvi Alid dhe prodhuesi i fishekëve Rusid Ljuda u shitnin tetovke kryengritësve. ${ }^{43}$

Pavarësisht faktit se dëmtoheshin, këto armë ishin tejet të përhapura ndër shqiptarët, dhe ato i blinin edhe serbët nga zonat përreth Vranje për luftën kundër turqve. Kushtonin shumë pak. Në fund të shekullit XIX, një Martina kushtonte 1 lirë ari turke dhe gjatë periudhës 1900 - 1903, çmimi ishte 1 e 1/2 - 2 lira turke, ndërsa Martini e fabrikës shtetërore osmane kushtonte 4-6 lira turke. Gjatë kryengritjes antiturke të Ditës së Shën Ilisë, më 2 gusht 1903, çka në Maqedoni njihet si Ilinden, çmimi për një Martina ishte më pak se 1 lirë turke.

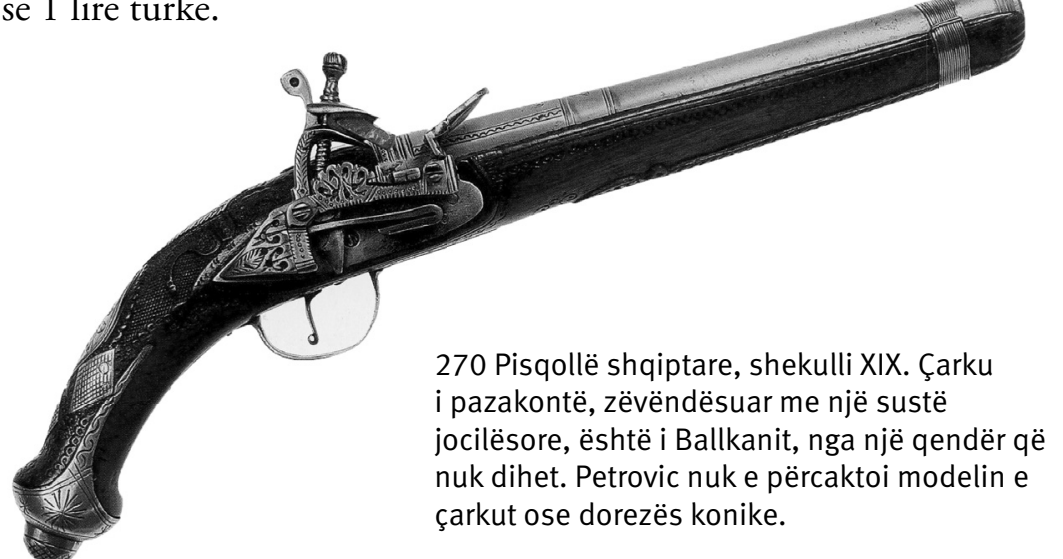

36 Lape, 1951, p. 11

37 Petrov, 1930, p. 10

38 Lape, 1951, p. 2

39 Petrovic, Oruzarskata dejnost, 1970, p. 213

40 Siljanov, 1933, p. 82. Gras rifle: French Model 1874, calibre 11 mm (0.433 in.), boltaction, single-shot rifle designed by Captain Basile Gras (1836-1904).

41 Lape, 1951, p. 11

42 Simovski, 1953, p. 19

43 Po aty. 
Pas Revolucionit Xhonturk prodhimi dhe shitja e armëve në Tetovë u ndalua me një urdhër zyrtar të datës 7 prill 1908, por fishekët vijuan të vinin kontrabandë nga Serbia dhe karvanët vijuan rrugëtimin për tek rebelët.

E alarmuar nga kërcënimi i nacionalizmit nëpër perandori, qeveria turke kaloi në 1903-8 legjislacionin kundër armëtarëve privatë, i cili i detyronte disa prej tyre të punonin nëpër fabrikat shtetërore të Stambollit. Në fund të shekullit XIX, Tetova kishte ende gjashtëdhjetë punishte armëtarësh, por nga viti 1905 ky numër kishte zbritur në pesëdhjetë. Shumë armëpunues tetovarë u thirrën nën armë në ushtrinë turke, si juzbasa ose armëtarë, ndërsa brezi pasardhës u punësua nëpër artileritë e riparimit të Stambollit. Shumë armëtarë i përdorën mjeshtëritë e tyre për artikuj të tjerë, por disa vijuan të punonin në fshehtësi, sidomos me riparimin e armëve. Druajtjet e turqve kishin qenë të sakta, pasi në kryengritjen shqiptare të 1910-11-ës, Martinat e Tetovës patën një rol të madh dhe prodhimi i tyre flitej se arrinte rreth pesëdhjetë në javë. Në 1912 kishte ende njëzet punishte armëtarësh në Tetovë, të cilët teorikisht riparonin armë. Gjatë Luftës së Parë Botërore, vërshuan në vend armët e zjarrit ushtarake, të prodhuara në masë: armëtarët me mjeshtëritë e tyre tradicionale mbijetuan dhe u prodhuan edhe disa armë sportive, por aty nga viti 1964 kishte mbetur vetëm një punishte, që zotërohej nga Djordje Surdic.

Prodhimi i hutës ose Martinës, vazhdoni deri në 1939/40 në Shkodër dhe Elbasan, ndonëse esnafi i Elbasanit u mbyll në Luftën e Parë Botërore. Armëtari i fundit i Elbasanit, Cen Karadaku, vdiq në 1943, pas një karriere pesëdhjetëvjeçare. Djemtë e tij vazhduan të punojnë metalin, por për artikuj të tjerë. Martinat bëheshin edhe në Prizren dhe Gjakovë të Kosovës. Në Berat një nga familjet më të mëdha armëpunuese quhej Mbrica: Akatangiel Mbrica dhe i biri Pal Mbrica punuan në shekullin XIX. Në Korçë brezat e familjes Peristeri farkëtuan armë deri në mesin e shekullit XX; pas kësaj $\mathrm{u}$ prodhuan ose u dekoruan vetëm një numër i vogël armësh sportive dhe armëpunuesit, zejtarët e fundit ishin ende gjallë në fund të mijëvjecarit. Carver e përshkruan popullaritetin e gjatë të Martinës ose hutës, pasi i kishte parë në punishten e një armëpunuesi të një zone të thellë në Shqipërinë verilindore në 1997, duke u përgatitur për përdorim përtej kufirit në luftën e Kosovës. ${ }^{44}$

44 Carver, 1998 


\section{Albanon}

Revistë kulturore

\section{Bibliografi}

Alexander, David, The Arts of War, London, 1992

Bjelokosic, L. G., 'Zbircica oruzja' [A small collection of arms], Zora, 3/3, Mostar, 1898

Boccia, Lionello Giorgio Armi d'attacco, da difesa e dafuoco: la collezione d'armi del Museo d'Arte Medievale e Moderna di Modena, Modena, 1996

Carver, Robert, The Accursed Mountains, London, 1998

Curcic, Vejsil, 'Starinsko oruzje u Bosni i Hercegovini' [Ancient arms in Bosnia and Herzegovina], Çaushi, A., Dyfekçinj e armëtarë nëElbasan (Artisans de fusils et armuriers a Elbasan), Etnografia Shqiptare, no. 1, Tirana, 1962, pp. 251-83

Daskalov, Nikola, and Kovacheva, Vyara, Weaponry of the Past, Sofia, 1989

Daskalov, Nikola, and Kovacheva, Vyara, Weaponry of the Past, Sofia, 1989

Drishti, Riza X, Armët dheArmëtarët Shqiptarë [Weapons and Albanian warriors], Tirana, 1976

Glasnik: Hrvatskogdrzavnog muzeja u Sarajevu, god. LV, 1943 [Sarajevo], 1944, pp. 21-226

Han, J. G., Putovanje krozporeëinu Drima i Vardara [Travel through the river basin of the Drim and the Vardar], Beograd, 1876

Hobhouse, John Cam, A Journey through Albania and the Other Provinces of Turkey in Europe and Asia to Constantinople in the Years 1809 and 1810, London, 1813

Karadzic, Vuk S., Crna Gora i Boka Kotorska [Montenegro and Boka Kotorska], Beograd, 1953

Kendrick, Tertius, The Ionian Islands, London, 1822

Kozlovski, Todor, Old Firearms of the Bulgarians, Plovdiv, Bulgaria, 1981

Lape, Lj., Snabduvanje na ohridskite revolucioneri so oruzje do Ilindenskoto vostanje [Arms supply to the revolutionaries of Ohrid until the Ilinden uprising], Skopje, 1951

Lord Byron, Childe Harold's Pilgrimage, 1812

Petrov, N., 'Stranice od moja dnevnik na 1901' [Pages of my diary, 1901 ।, Ilustracija Ilinden, 5 [Sofia], 1930 
Petrovic, Durdica Oruzarskata dejnost vo Makedonija vo predilindenskiot i vo ilindenskiotperiod: zbornik Ilinden, 1903 [Activity of armourers in Macedonia prior to and during the Ilinden uprising: journal Ilinden, 1903], Skopje, 1970, pp. 209-26; - 'Veze Makedonije i Albanije na primeru proizvodnje rucnog vatrenog oruzja $\mathrm{u}$ Debru $\mathrm{u}$ XVIII i XIX veku' [Relations between Macedonia and Albania as seen through the manufacture of portable firearms at Debar in the 18th and 19th centuries], Zbornik Muzejaprimenjene umetnosti, 19-20 [Beograd], 197576, pp. 41-56; -'Trgovina proizvodima domacih oruzara u jugoslovenskim oblastima pod Turcima u XVIII i XIX veku' [Trade in armourers' products in the Yugoslav regions under Turkish rule in the 18th and 19th centuries], Glasnik Zemaljskog muzeja Bosne i Hercegovine, Etnologija, n.s., 43/44 [Sarajevo], 1989

Pouqueville, F. C. H. L., Travels in Epirus, Albania, Macedonia and Thessaly, London, 1820; facsimile reprint, ed. J. Pettifer, Classic Balkan Travel, [London, 1998]

Siljanov, $\boldsymbol{H}$., Osvoboditelnite borbi na Makedonija [The struggles for liberation in Macedonia], 1, Sofijas, 1933

Simovski, T., Za ucestvoto na malicinstvata vo ilindenskoto vostanie [For the participation in the Ilinden uprising], Skopje, 1953

Temesvary, Ferenc, Arms and Armour, Hungary, 1983

Vukmanovic, Jovan, 'Jedna zbirka crnogorskog oruzja' [A collection of Montenegrin arms], Glasnik [Ethnographical Museum in Cetinje], 1, 1961, pp. $7-21$ 